German Data Forum

(RatSWD)

\title{
RatSWD
}

Working Paper

No. 140

\section{Multidisciplinary Household Panel Studies under Academic Direction}

Jürgen Schupp and Joachim R. Frick

April 2010 


\section{Working Paper Series of the German Data Forum (RatSWD)}

The RatSWD Working Papers series was launched at the end of 2007. Since 2009, the series has been publishing exclusively conceptual and historical works dealing with the organization of the German statistical infrastructure and research infrastructure in the social, behavioral, and economic sciences. Papers that have appeared in the series deal primarily with the organization of Germany's official statistical system, government agency research, and academic research infrastructure, as well as directly with the work of the RatSWD. Papers addressing the aforementioned topics in other countries as well as supranational aspects are particularly welcome.

RatSWD Working Papers are non-exclusive, which means that there is nothing to prevent you from publishing your work in another venue as well: all papers can and should also appear in professionally, institutionally, and locally specialized journals. The RatSWD Working Papers are not available in bookstores but can be ordered online through the RatSWD.

In order to make the series more accessible to readers not fluent in German, the English section of the RatSWD Working Papers website presents only those papers published in English, while the the German section lists the complete contents of all issues in the series in chronological order.

Starting in 2009, some of the empirical research papers that originally appeared in the RatSWD Working Papers series will be published in the series RatSWD Research Notes.

The views expressed in the RatSWD Working Papers are exclusively the opinions of their authors and not those of the RatSWD.

The RatSWD Working Paper Series is edited by:

Chair of the RatSWD (2007/2008 Heike Solga; since 2009 Gert G. Wagner) Managing Director of the RatSWD (Denis Huschka) 


\title{
Multidisciplinary Household Panel Studies under Academic Direction
}

\author{
Jürgen Schupp and Joachim R. Frick
}

German Socio-Economic Panel (SOEP) (jschupp[at]diw.de, jfrick[at]diw.de)

\begin{abstract}
This paper concentrates on the trends in peer-reviewed longitudinal panel studies under scientific direction. Household panel studies have succeeded in broadening their disciplinary scope. Numerous innovations such as questions dealing with psychological concepts, and age-specific topical modules, physical health measures, measures of cognitive capabilities, behavioral experiments have been incorporated into various panel studies or are soon to be introduced. In the UK, the household panel study Understanding Society comprising 40,000 households was launched in 2009 and recently added an "innovation sample"; in the Netherlands, the new LISS household panel study launched in 2006 with over 5,000 households will be used for the testing of innovative measurement methods.

The microdata from household panel studies like PSID (US Household Panel Study), BHPS (the predecessor of UK HLS), HILDA (Australian Panel Study), and SOEP (German Socio-Economic Panel) are in continuously high demand by the research and policy advisory community. More important than "discovering" entirely new survey areas is "tailoring" the details of existing survey content to new, more specific (theoretical) questions, and thus maintaining proven and widely used elements of survey content. In the years to come, "tailoring" survey content will be the real challenge facing surveys that are integrated into the existing research infrastructure like HILDA, LISS, PSID, SHP (Swiss Panel), SOEP, and Understanding Society.

We argue that, in the future, household panel studies should be designed to take the "margins" of the life course more fully into account. Indeed, household surveys are ideally suited to gather comprehensive data on these life phases. They can be improved, on the one hand, by including specific topics about the fetal phase of life and early childhood of children born into the panel, and on the other hand, by including better information about late life and death. In the middle of the life course, improved questions on income, savings, consumption, and wealth, as well as psychological constructs will play a central role, as will specific "event-triggered" questionnaires on central life occurrences such as marriage, divorce, and entry into and exit from unemployment.

In order to substantially improve the statistical power of long-term longitudinal data, we propose an absolute minimum number of observations of about 500 persons per birth and age cohort. As of now, only the British Understanding Society will meet this target. A positive side-effect of such an enlargement is a significantly improved potential for analyses of relatively small groups within the population: for example, lone parents or specific immigrant groups. Another positive side-effect would be an improved potential for regional analyses. For example, in Germany, a cohort size of about 500 persons implies a survey sample size of about 20,000 households, which is large enough for analyses in the majority of federal states.

Multidisciplinary panel studies will become even more important if they are accepted as reference datasets for specialized surveys that are independent of the original panel study (e.g., observational studies such as twin studies and laboratory or intervention studies). To enhance this important function, new types of service are needed, including advice on special surveys and possibly also data preparation for special surveys.
\end{abstract}

Keywords: household panels, multidisciplinary surveys, reference datasets

JEL Classification: A12, C81, C83, C93, C99, H2, H3, H5, I12, I21, I3, J1, J2, J3, J6, J71 


\section{Introduction}

"Longitudinal surveys, which collect information about the same persons over many years, have given the social sciences their Hubble telescope. Both allow the observing researcher to look back in time and record the antecedents of current events and transitions” (Butz and Boyle Torrey 2006: 1899).

If we look back in survey history, social scientists began as early as the 1930s to design a new kind of longitudinal study: the panel survey (Lazarsfeld and Fiske 1938). Panel surveys measure the same variables in the same individuals at two or more points in time. One of the first panel studies was conducted in the US in 1940 in the field of political science (Lazarsfeld et al. 1944). The focus was on the effect of election campaigns, the mass media, and personal communication about politics and causal relationships. Known as the "Erie County Study,” Lazarsfeld's study was conducted on a sample of about 600 persons who were surveyed repeatedly over a period of more than six months in seven panel waves. This study remains a model for election studies in political science up to the present day.

In the methodological literature, panel surveys are often described as having a “prospective longitudinal design” (Featherman 1980). In such a design, a group of individuals are interviewed, tracked, and reinterviewed at least once at some future point in time. A "retrospective" panel design, on the other hand, entails collecting data on only one occasion. The longitudinal dimension of such a study is obtained by asking people to recall what things were like at some earlier point in time, as well as at present (de Vaus 2001). This means that it is not strictly necessary to use a longitudinal research design to collect longitudinal data, although there are conceptual distinctions among different types of longitudinal data (Featherman 1980). Here, a crucial question is how reliable retrospective data are as substitutes for direct observations of the past (e.g., concurrent respondent reports in longitudinal panels, independent records, etc.). Such retrospective designs have been used in sociology to collect event history data covering the entire life course. An example of such a study is the German Life History Study (Brückner and Mayer 1998).

In developmental psychology, longitudinal surveys have a clear prospective focus:

"Longitudinal methodology involves repeated time-ordered observation of an individual or individuals with the goal of identifying processes and causes of intraindividual change and of interindividual patterns of intraindividual change in behavioral development” (Baltes and Nesselroade 1979: 7).

Together with total population designs, which are representative from both a cross-sectional and a longitudinal perspective, longitudinal panel surveys are described as advantageous in several respects:

“Total population designs and longitudinal panel designs can be used for practically any type of longitudinal analysis, given a sufficient number of cohorts and measurement periods. Other designs are more limited, and their appropriateness must be judged in the context of a particular research problem” (Menard 2002: 33). 
High-quality household panel surveys begin, like cross-sectional surveys, with a random sample of a set of households and of the individuals within those households. For decades, the only mode of data collection was through face-to-face, paper-and-pencil interviews. But an increasing variety of other modes of data collection have become common, some reflecting technological advances. For example, mail surveys and web-based surveys are now also being used (e.g., in the Dutch LISS panel). In addition, different modes of assessment are used. In panel surveys, trained interviewers conduct health tests and tests of cognitive ability (e.g., in SHARE). Panel surveys differ from cross-sectional surveys in that they continue to follow sampled individuals at regular intervals, usually once per year (wave). Adhering to the basic “follow-up rules” determining who to contact and interview again, household panel surveys produce data on changes in the demographic, economic, and social conditions of their members and thus attempt to remain representative of the cross-sectional population as well. This is in contrast to individual panel studies covering entire birth cohorts of individuals in the population. ${ }^{1}$ These panels represent their cohorts as they age and may gradually decline in representativity for the original age group. The household panel surveys discussed in the following section can be defined as: multiple repeated observations (usually once per calendar year) for age-heterogeneous individuals within their household context and based on a random sample of all (private) households of a country. Their theoretical concept and variables cover a wide range of social and economic issues.

One may ask whether the Hubble telescope (by Butz and Boyle Torrey 2006: 1899) really is the right metaphor for panel studies. After all, since microdata is involved, the comparison with a microscope might seem more appropriate. ${ }^{2}$ The answer is twofold. First, panel data have a temporal dimension (as noted by Butz and Boyle Torrey): they do not deliver just a "snapshot," but allow us to actually look back in time (just as telescopes do). Second, panel studies are expensive compared to other studies in economics and the social sciences. Thus, in terms of money, the comparison with a highly sophisticated but expensive device such as the Hubble telescope is much more appropriate than the comparison with more economical microscopes.

This paper gives a summary of current developments in longitudinal household surveys under academic direction. For an overview covering all the various types of panel and cohort studies, see Wissenschaftsrat (2010).

\footnotetext{
1 Like the longitudinal design of the 1958 National Child Development Study and the 1970 British Cohort Study (Schoon 2006) and the Millenium Cohort Study or the Olympic Cohort in 2012.

2 Senator Jürgen Zöllner, who is responsible in Berlin's government for education and research, once asked this question.
} 


\section{Status Quo of Multidisciplinary Household Panel Studies under Academic Direction}

The success story of large-scale household panels started about 40 years ago, with the Panel Study of Income Dynamics (PSID) (Brown et al. 1996). Only household panel designs like the PSID, or the designs of the German Socio-Economic Panel (SOEP) and British Household Panel Study (BHPS), represent all individuals and households in the population and contain an endogenous mechanism for representing demographic changes in existing households caused, for example, by new entrants (birth, immigration, regional mobility) as well as dropouts (death, emigration) reflecting the dynamics of the underlying population.

Household panels start with a representative sample of households and a representative set of individuals residing in those households. If the tracking and following rules used in household panels call for attempted interviews with all household members in the original sample, all individuals born to the original sample members, and any individuals who have moved into those households in the meantime (see Kroh et al. 2008), then this prospective panel design continues to provide a representative cross-sectional picture of the underlying population over the life of the panel. Except for immigration into newly founded households from outside the sampling frame, all demographic events (births, deaths, emigration, and events like divorce and the departure of children from their parents' homes) are covered by a high-quality household panel design. Immigration has to be handled through supplemental samples (see Schupp and Wagner 1995).

Due to initial non-response and attrition of panel respondents over the course of time, high-quality response and attrition analyses and carefully designed re-weighting strategies are crucial to achieve representative population estimates in panel studies (Ernst 1989; Rendtel and Harms 2009). Population estimates (indicating representativity) are an important issue, because all longitudinal and cross-sectional results of the household panel survey are in continuously high demand in both the research and policy advisory community (e.g., Wissenschaftsrat 2009: 56).

Today, some of the most widely used long-running household panel studies that seek to provide a representative view of the entire population of a given society include the BHPS (British Household Panel Study), the Household Income and Labour Dynamics in Australia Survey (HILDA), the Swiss Household Panel Study (SHP), and the German Socio-Economic Panel Study (SOEP). These panels differ from the individual longitudinal studies developed by sociologists in both design and scope, using an extended household concept to measure subjective as well as objective variables. They also differ from the longitudinal cohort studies developed by epidemiologists and psychologists. 
Over the course of time, household panel studies have expanded in scope - driven by new research questions of their Principal Investigators (PI) and by the demands of their scientific user communities - and now cover a number of new research questions, some dealing empirically with the "utility" of respondents and the parameters of their utility function. These include happiness and satisfaction with life, health, “other preferences” (trust, fairness, and reciprocity), risk, and inequality aversion.

"Biomarkers" are another exciting new area of research providing non-standard measurement of a respondent's "biological and medical status.” One such biomarker is "grip strength,” which can be used as an indicator of health (Hank et al. 2009).

“Indeed, biomarkers on social surveys may well reveal more about subjects' predispositions and their ancestry than do their verbal responses on which social scientists have historically depended. Over the past two decades, the theory of evolution has influenced parts of economics and psychology, and to a lesser extent sociology, anthropology, and political science” (Butz and Boyle Torrey 2006: 1899).

In other words, socio-economic panel studies are incorporating an increasing number of concepts from the fields of medicine and psychology. This development has been propelled by the emergence of new research questions, and its pioneers include the Health and Retirement Survey (HRS), the English Longitudinal Study of Ageing (ELSA), and the Survey of Health, Ageing and Retirement in Europe (SHARE) ${ }^{3}$. The latter study provides a new, comprehensive, international view on aging, but does not cover the population under 50 years of age.

The research community unanimously supports the call for more complete data on the individual life course within the household context, and for improved opportunities to analyze intergenerational transmissions of behavior and social structures and thus to disentangle the impacts of "nature" and "nurture." Outside of the social sciences, this kind of analysis is called "behavioral genetics” (e.g., Plomin et al. 2008). And, in fact, household panel data expand the possibilities for doing research along this line because of the variety of different intergenerational relationships captured in the households surveyed.

Another methodological advantage of panel data is the possibility to make causal inferences: natural experiments created through inherent differences between institutions and countries. The international comparability of data is therefore a central objective in the governance of social statistics and longitudinal studies, and this can only be guaranteed through the optimal design of organizational and financial structures.

3 Thus, while SHARE is also a prospective panel study, it is not a fully-fledged household panel, but rather an extended cohort study. The strength of SHARE is its worldwide multi-country coverage (http://www.share-project.org/). 
The Cross-National Equivalent File (CNEF, based at Cornell University in Ithaca, NY, US) provides a common database derived from existing national panels, namely PSID (US), SOEP (Germany), BHPS (UK), SLID (Canada), SHP (Switzerland), and HILDA (Australia) (see Frick et al. 2007). And all successful household panel studies under academic direction demonstrate that the real added value of panel studies can be reaped only after ten waves or more.

To put it succinctly, the major household panel studies under academic direction (as mentioned above) stand for theory-based data collection, not just for more data and better statistics. And because such household panels are expensive, all of them are part of the national and/or international research infrastructure (Elias 2008).

\section{Recommendations}

\subsection{Governance}

Two prime examples of good governance in large-scale surveys are the European Social Survey (ESS, a set of repeated cross-sectional surveys run by political scientists) and SHARE (a truly interdisciplinary longitudinal study of economics, sociology, and health). Both surveys provide datasets that form an infrastructure for addressing theory-driven research questions. Unfortunately, initiatives for cross-nationally harmonized household panels, which are more expensive than studies like ESS, are often not research-driven - for example, the ECHP (European Community Household Panel), which provides annual panel data for the period 1994 to 2001. EU-SILC (European Union Statistics on Income and Living Conditions), the follow-up survey of ECHP, has a reduced panel component of just four waves focusing on short-term measurement of income and poverty dynamics. EU-SILC will not, however, allow for the kind of in-depth life course analysis necessary for testing theoretical concepts and hypotheses in the social and behavioral sciences.

We believe that the following list of recommendations can help to ensure good governance of household panel studies under academic direction:

\section{- Ensure medium-term funding!}

Household panels - like other prospective longitudinal studies - crucially require stable research questions, survey content, and fieldwork. Annual funding - for example, oneyear contracts with fieldwork organizations - cannot guarantee the necessary degree of stability and reliability. Although auditors and accountants may not like medium-term and especially not long-term funding or contracts, medium-term funding (covering at least five years) is the absolute minimum in the case of household panels. And to ensure the quality 
of the fieldwork and the longitudinal data, ten-year periods of funding and contracting are even better. Other means of quality control than short funding periods must be found to ensure the quality of the panel. In case of panels under academic direction, this is not difficult to achieve because all academic panel studies are under the permanent supervision of advisory boards (and under the “supervision” of users).

- Get the user community involved!

Ongoing panel studies need ideas from their users. However, it is an open question how best to gather user input. Funding agencies are attempting more and more to promote competition. In our opinion - based not least of all on the experience of the British Household Panel Survey (BHPS) - the theoretical and methodological standards of major household panels cannot be raised simply by holding an annual competition among users to suggest an additional "One Minute Question.”" This was used occasionally by BHPS, but is no longer being used in the new UK panel Understanding Society. While such an approach may produce mainstream add-ons, we feel it is less promising than the approach adopted by the SOEP (which has already undergone pilot testing in recent years): that of focusing on close cooperation with users who are prepared to invest their time, energy, and even resources in pretesting, with the explicit aim of increasing the SOEP's long-term longitudinal potential.

- Oversample subgroups!

While gigantic sample sizes of 100,000 households would ensure sufficient sample sizes in the near and more distant future, with high statistical accuracy for all relevant subgroups of the population, they are not realistic in terms of funding. Thus, the oversampling of subgroups is a permanent issue for the governance of household panel studies. The new British panel Understanding Society, with a sample size of 40,000 households covering all of the British regions, is a good example, because even this large sample cannot cover immigrants in a sufficient manner. As a result, immigrants are oversampled. In terms of governance and funding, it is a difficult question whether oversampling of special groups should be done with household panels themselves or through related studies (with external funding) that use a fully-fledged household panel as a "reference sample." There is no clear-cut answer to this question. Whether oversampling should take place within a major household survey or by means of related studies must be discussed on a case-by-case basis.

4 This refers to a competition to create special questions, for which a specific amount of time will be allocated in the survey. 
- Be innovative!

The same is true for the use of "innovation samples" to address highly specified, theorydriven research questions that require specific variables and possibly also specific survey methods. Incorporating such aspects into an ongoing longitudinal survey has the advantage that one need not wait for many years before doing longitudinal analysis. A longitudinal innovation sample that is open to new kinds of measurement is of much higher research value than a new cross-sectional innovation sample. The Dutch LISS panel could possibly become a model for future innovation samples. ${ }^{5}$

- Push for related studies!

A representative, large-scale household panel sample can serve as a control sample for intervention studies that may be carried out using parts of the innovation sample or as related studies (Anger et al. 2009; Siedler et al. 2009).

\subsection{Important areas for substantive enlargements and methodological improvements in the survey programs of household panels ${ }^{6}$}

In order to understand human life and human society better, we need to understand human beings as fundamentally social beings. It is thus important to study the range of networks (and areas) in which humans live. But at the same time, there is increasing evidence that sociality is not only a cultural phenomenon (highlighting the importance of intergenerational networks as mentioned above), but that it is also - to a degree that varies between individuals - "hardwired” into our genome through epigenetic inheritance (Fehr 2009). International developments suggest the value of more systematically surveying a number of variables on the biological foundations of human life (biological and personality characteristics) in a number of areas, and of studying the networks in which individuals, their families, and their households are embedded.

This systematic approach to measurement is not only the result of theoretical improvements but is also driven largely by new technological opportunities for measurement and analysis (e.g., experiments in the lab and in the field, surveys using the Internet and mobile phones, methods of collecting biomarkers and analyzing the genome). In fact, this new analytical approach currently appears to be driven even more by new technologies than by

\footnotetext{
The governance of this innovative household panel is documented at http://www.lissdata.nl/lissdata/.

Without challenging the importance of the following issues, we do not address here questions of improved data management (e.g., by means of the "long format" and DDI), data distribution (Rendtel 2009), and improved IT technologies (see, e.g., www.opendatafoundation.org). We also do not discuss the possiblities of "paradata," which deliver information about the fieldwork process (Kreuter and Casas-Cordero 2010). We do believe that paradata are of utmost importance for the analysis and control of fieldwork processes, attrition analyses, and weighting (Schräpler et al. 2010).
} 
new theoretical insights. This might seem to contradict textbook reasoning about the primacy of scientific theory over pure measurement possibilities, based on the idea that empirical methods should only be used to test the empirical implications of specific theories. "Measurement without theory" is an old and serious criticism lodged against empirical research and data collection. However, in the history of science, we find numerous examples demonstrating that new measurement methods often precede and indeed pave the way for theoretical reasoning. One prominent example is Galileo’s telescope, first used 400 years ago, in the year 1609 in Padua. Although it was invented for practical purposes, it revolutionized not only the measurement of the visible universe, but a lot of theories too. In the future, "new eyes” will show us further "new skies” (Kanipe 2009).

It is self-evident that the ambitious goal of comprehensively measuring human life trajectories could easily overtax respondents and lead to declining and, in particular, selective response rates. For this reason, we propose that for household panels requiring a high cooperation rate among long-term respondents, new survey methodologies should be tested, such as a standardized "multi-method approach" and "matrix sampling." In matrix sampling, missing values are deliberately created (and later replaced with imputed values) by randomly assigning certain questions that are not to be asked to particular subsamples. This reduces the burden of the number of questions to be answered. Though appealing in theory, this method will be challenging to implement successfully in a long-running survey. It may also be worthwhile to use more special proxy questionnaires for the youngest panel "members" who are not able to respond on their own in early childhood, or for those who cannot participate due to temporary absence or bad health.

The comprehensive survey program developed for, and partly realized in, the classic social scientific survey of the "Unemployed of Marienthal” (see Jahoda et al. 1933) appears more promising than ever. Yet since the 1970s, with the growing popularity of standardized survey research, the methodology used in the Marienthal Study has been gradually abandoned. Today, new technologies make more accurate and comprehensive empirical research possible.

Among geneticists, who focus on heritable influences on human behavior, it is broadly accepted that social context is essential for understanding human outcomes. Typically, several different genes and environments play a role in certain outcomes, and it is therefore crucial to study the interactions between the two mechanisms to understand the complexities and dynamics of human behavior. On the other hand, recent work by sociologists and economists provides further evidence that individuals do not respond to societal contextual influences in a unique or socially contingent way. This means that only multidisciplinary collaboration 
integrating genetic approaches can be expected to produce new insights into this complex relationship (Freese 2009; Guo et al. 2008). The SOEP study has already taken initial steps in this direction, aimed at an interdisciplinary enlargement of the research design (Schupp and Wagner 2010).

- Better data on the start and end of life

Thanks to their longitudinal design, household panel studies are ideally suited to trace the biographies of birth cohorts from the very beginning to the terminal phases of life.

In an ongoing household panel study, membership does not begin at birth (as is the case in conventional cohort studies) but indeed prior to birth, through the participation of one or both parents in the study. The potential of this unique feature of household panels can be exploited by asking mothers-to-be questions about pregnancy and (very) early childhood. These data allow the economic and social conditions at conception and during pregnancy to be taken into account as aspects defining the individual life course.

Household panels not only provide the opportunity to observe the life course from the very beginning, but also shed light on the terminal phase of life. ${ }^{7}$ However, when health declines in later years, respondents often become unwilling or incapable of responding on their own. In these cases, proxy interviews are a useful alternative, yet they remain relatively uncommon. Furthermore, it is often necessary to follow respondents from private households into retirement or nursing homes (Jürges 2009).

- Consumption and savings

Up to now, consumption has generally not been covered well by household surveys. However, in theoretical terms, consumption is an important measure of economic wellbeing at the individual and the household level. Due to the complexity and respondent burden involved in surveying high-quality data on consumption (levels and patterns), it is widely believed that well-being can be proxied by income. Obviously, this is less than adequate, since income may indeed be much more volatile than consumption, necessitating information on income (a flow measure) as well as on the process of (dis)saving to smooth consumption.

In order to better understand human behavior in this context, the collection of information on wealth (stock measure), as well as on changes in wealth holdings over time, appears to be especially fruitful for long-running household panel surveys like

7 See also Romeu Gordo et al. (2009) about household panels as a resource for research on aging, and Kröger (2008) for a pretest of the SOEP exit questionnaire. 
SOEP (see Frick et al. 2007). Recent advancements in the collection of expenditure data, rather than consumption data, have been made in the Australian HILDA survey, providing clear evidence that income poverty is different from consumption poverty as well as from low wealth (see, e.g., Headey 2008). The 2010 wave of SOEP will, for the first time, include a short assessment of expenditures in the most important domains (housing, nutrition, education, family transfers, and savings).

\section{- Better measures of competencies}

In all household panel surveys, human capital has traditionally been operationalized solely by measuring educational attainment as the highest level of schooling or vocational training completed. It seems "natural” to improve household panel survey instruments by collecting better data on the cognitive competencies of respondents using standardized measurement procedures (Schupp et al. 2008). In addition, there should be increased efforts to record what are known as non-cognitive capabilities, that is, competencies that are not necessarily acquired in educational institutions but (to a greater extent) at home during early childhood. The SOEP survey program will be extended in a number of ways in the coming years to cover the area of skills (Grabner and Stern 2008; Uhlig et al. 2009). ${ }^{8}$

- Health and the biological foundations of social and economic behavior

Despite the growing interest in integrating biomarkers into surveys, we are convinced that the collection of biomarkers in household panel studies in an unrestricted manner, and solely to address medical research questions, would not be useful or even practicable. Attempting to move in the direction of medical research would impose too high a burden on respondents (as regards the scope and duration of the survey) and would impede the useful division of labor between different methodological approaches and surveys. Rather, a survey of this kind would be a perfect example of a "related study."

However, biomarkers that can be used to enhance social and behavioral science analyses, and in some cases consolidate their results considerably, promise to be highly useful (National Research Council 2008). One of the reasons is that longitudinal surveys deliver, through repeated measurement, very reliable pictures of phenotypes (the term used by life scientists to describe organisms as the result of the interaction between genotype and environment). Thus, with longitudinal data produced by social scientists, we

8 See the research network “Nicht-kognitive Fähigkeiten: Erwerb und ökonomische Konsequenzen” (Non-Cognitive Skills: Acquisition and Economic Consequences). For more information, see http://www.zew.de. 
are much more likely to identify the biological foundations of human behavior than with converse approaches: for example, if life scientists tried to enrich biobanks with social variables.

\section{- Other measurement improvements}

A new technology, and an alternative to item sets, is what are known as factorial designs with vignettes. These questions ask respondents very detailed questions about fictitious situations and decisions. This approach is a kind of quasi-experiment (Sauer et al. 2009).

New technologies have opened up completely new possibilities for measuring human behavior and biographies in the context of personal networks and local environment. We believe that these new measurement possibilities are especially valuable within prospective panel studies: such new technologies can help to measure behavior between regular panel waves (which are usually conducted once per calendar year) and to measure networks and environments. We briefly mention some of these new opportunities without having the space to discuss them in depth. Mobile phones can be used as devices for sampling between regular panel waves. In fact, this is being done already (Riediger 2009; Riediger et al. 2009). It will be relatively straightforward to use this same technology to locate respondents who have moved and collecting photos and sound bytes from everyday life will be a further step (Mehl et al. 2007). Even monitoring the physical status of respondents over the course of a day (or several days) with systems currently used by physicians to monitor their patients would be possible (Wrzus et al. 2010).

Networks and local environments of respondents can be measured by links to their Facebook accounts (if respondents give permission). And on the basis of respondents' statements, links can be created to organizational data (e.g., on employers or childcare facilities) (Liebig 2009).

In addition, panel studies can gradually be enhanced by carrying out internal surveys of contextual data. At SOEP, we intend to start with specific surveys that gather data on organizational contexts from 2011 onwards. These will include targeted surveys in childcare centers, schools, and at respondents' workplaces. In 2007, we administered such a pre-test and obtained positive results. It showed that respondents are by and large willing to pass on the addresses of their childcare centers, schools, and employers (Schupp et al. 2008). In 2008, ALLBUS carried out its first survey of this kind ${ }^{9}$ at the workplaces of all

9 The ALLBUS Organisational survey is being led by Stefan Liebig, who also provided advice to the SOEP when first pilots were being carried out during pretesting (for first results on such an LEE dataset, see Meyermann et al. 2009). 
employed survey respondents; the results will be used to lay the groundwork for similar questions.

Based on the private addresses of respondents, records can be linked to an increasing number of geo-coded data bases, providing information on the local weather or availability of local infrastructure, for example (Lakes 2009, Goebel et al. 2010).

Survey data and behavioral experiments also can be combined (Gächter 2008; Naef and Schupp 2009). Online games, for example, can be used to run behavioral experiments (Bell et al. 2009; Castronova and Falk 2009). And for special subsamples, in-depth studies are possible based on approaches of "qualitative social research" (Teddlie and Tashakorri 2003; Laurie and Sullivan 1991).

\subsection{Developments in sample design and fieldwork}

Sufficiently large cohort subsamples allow researchers to analyze the impact of new retirement regulations or measures like the "child-raising allowance" in Germany. To meet our objective of providing statistically reliable information on groups of individuals born in the same year (age cohorts), we consider 500 cases per cohort to be a minimum. With about 500 observations per birth cohort, a researcher can analyze how the new policy instrument works for two very similar birth cohorts: one that is affected by the new law and one that is not. Another example is migration research, which profits similarly from larger samples (Haug 2009; Farwick 2009).

Possible developments in household panel sample(s) are not limited to just enlarging sample size and overall statistical power. The inclusion of special populations (in the case of SOEP, groups like immigrants and high-income households) is another possibility. And not only socio-economic subgroups of the population can be of interest: twins are also candidates for oversampling as a genetically interesting subgroup (Spinath 2008).

In the context of aging societies in Germany and many other Western countries, the coverage of persons in institutions needs to be improved - particularly individuals in (residential) nursing homes. Here the main focus should not be on achieving representative coverage of the institutional population as such, but on covering the life transition from private household to institutional care. This kind of longitudinal data is of high scientific and practical importance for better understanding health changes in old age, intergenerational relations, the relevance of institutional care arrangements for the individual life course, and, last but not least, the process of dying in modern societies. At present, household panels tend to be confronted with non-response when elderly respondents move into (nursing) homes. 
Here, the difficulties of interviewing persons affected by dementia constitutes a major hurdle; in this special case, the option of having care providers conduct proxy interviews requires further investigation.

International migration and migration dynamics play an increasingly significant role in society. In 2006, more Germans left their native country than ever before, except for the emigration wave of the 1950s. In household panel surveys, respondents moving abroad are no longer included in the sample. At SOEP, groundwork has already been undertaken for surveying abroad. Respondents who have left Germany since 2004 have been contacted, and surveys have been conducted in writing. ${ }^{10}$ The hope is that this will make it easier to reintegrate these individuals into the standard sample when and if they return to Germany, since they will never have left the sample completely. Obviously, following internationally mobile individuals will require very sophisticated fieldwork. However, in light of the harmonization of household panel surveys within the European Union, we expect increasing research interest in following mobile EU citizens across national borders to gain a better understanding of the motives and the consequences of mobility.

\section{Concluding Remarks}

Data sets generated from multidisciplinary panel surveys are usually extremely rich in analytical potential. At the same time " $(\mathrm{t})$ he richness of panel data is of value only to the extent that the data set is analyzed, and analyzed in a timely manner. Running a panel survey is like being on a treadmill: the operations of questionnaire design, data collection, processing and analysis have to be undertaken repeatedly for each successive wave. There is a real danger that the survey team will become overwhelmed by this process with the result that the data are not fully analyzed. To avoid this danger, adequate staffing is needed and a wellintegrated organization needs to be established” (Kalton and Citro 1993: 212).

Multidisciplinary household panel surveys need an institutionalized organizational setting, and they are outstanding examples of the research infrastructure that is vital for the social and behavioral sciences. Aside from the group of principal investigators running these kinds of panel studies, they also crucially require a multidisciplinary user group active in analyzing the data and publishing results. An exchange of experiences between data producers and data users is also important. Data producers can work to lower the burdens on users - for example, the challenges of learning to work with complex data structures - by providing new

10 “Living outside Germany.” See, for first results, Schupp et al. (2008). 
technologies of data distribution, documentation, and training courses. On the other side, feedback from data users on their experiences with the data can act as the scientific foundation for improving multidisciplinary household surveys. A future prospect will be the establishment of a European network of household panels under academic direction, with the HLS in the UK and SOEP providing key longitudinal data on the European level (Elias 2008). 


\section{References:}

Anger, S. et al. (2009): Developing SOEPsurvey and SOEPservice: The (Near) Future of the German Socio-Economic Panel Study (SOEP). SOEPpaper No. 155.

Baltes, P.B. and Nesselroade, J.R. (1979): History and Rationale of Longitudinal Research. In: Nesselroade, J.R. and Baltes, P.B. (Eds.): Longitudinal Research in the Study of Behavior and Development. New York

Bearman, P. (2008): Introduction (Exploring Genetics and Social Structure). American Journal of Sociology 114 (S1), v-x.

Bell, M.W./Castronova, E. and Wagner, G.G. (2009): Surveying the Virtual World: A Large Scale Survey in Second Life Using the Virtual Data Collection Interface (VDCI). DIW Data Documentation No. 44.

Borghans, L./Duckworth, A./Heckman, J.J. and ter Weel, B. (2008): The Economics and Psychology of Personality Traits. The Journal of Human Resources 43 (4), 972-1059.

Brown, Ch./Duncan, G.J. and Stafford, F.P. (1996): Data Watch: The Panel Study of Income Dynamics. Journal of Economic Perspectives 10 (2): 155-168.

Brückner, E. and Mayer, K.U. (1998): Collecting Life History Data - Experiences From the German Life History Study. In: Giele, J.Z. and Elder, G.H. Jr. (Eds.): Methods of Life Course Research. Thousand Oaks.

Butz, W.P. and Boyle Torrey, B. (2006): Some Frontiers in Social Science. Science 312, 1898-1900.

Castronova, E. and Falk, M. (2009): Virtual Worlds as Petri Dishes for the Social and Behavioral Sciences. RatSWD Working Paper No. 47.

de Vaus, D.A. (2001): Research Design in Social Research. London.

Diewald, M. and Mayer, K.U. (2008): The Sociology of the Life Course and Life Span Psychology: Integrated Paradigm or Complementing Pathways? DIW Discussion Papers No. 772.

Elias, P. (2008): Providing data on the European level. RatSWD Working Paper No. 46.

Ermisch, J./Gambetta, D./Laurie, H./Siedler, Th. and Uhrig, S.C.N. (2007): Measuring People's Trust. ISER Working Papers No. 2007-32.

Ernst, L. (1989): Weighting Issues for Longitudinal Household and Family Estimates. In: Kasprzyk, D./Duncan, G./Kalton, G. et al. (Eds.): Panel Surveys. New York.

Farwick, A. (2009): Internal Migration Challenges and Perspectives for the Research Infrastructure. RatSWD Working Paper No. 97.

Featherman, D.L. (1980): Retrospective Longitudinal Research: Methodological Considerations. Journal of Economics and Business 32 (2), 152-169.

Fehr, E. (2009): On the Economics and Biology of Trust. Journal of the European Economic Association 7 (2-3), 235-266.

Freese, J. and Shostak, S. (2009): Genetics and Social Inquiry. Annual Review of Sociology 35, 107-128.

Frick, J.R. and Grabka, M.M. (2005): Item-non-response on income questions in panel surveys: incidence, imputation and the impact on inequality and mobility. Allgemeines Statistisches Archiv 89 (1), 49-60

Frick, J.R. and Grabka, M.M. (2007): Item Non-Response and Imputation of Annual Labor Income in Panel Surveys from a Cross-National Perspective. SOEPpaper No. 49.

Frick, J.R./Goebel, J./Schechtman, E./Wagner, G.G. and Yitzhaki, Sh. (2006): Using Analysis of Gini (ANoGi) for detecting whether two sub-samples represent the same universe: The German Socio-Economic Panel Study (SOEP) Experience. Sociological Methods \& Research 34 (4), 427-468

Frick, J.R./Jenkins, S.P./Lillard, D.R./Lipps, O. and Wooden, M. (2007): The Cross-National Equivalent File (CNEF) and its Member Country Household Panel Studies. Schmollers Jahrbuch 127 (4), 627-654.

Frick, J.R./Grabka, M.M. and Sierminska, E. (2007): Representative wealth data for Germany: The impact of methodological decisions around imputation and the choice of the aggregation unit. SOEPpaper No. 3.

Frick, J.R./Grabka, M.M. and Groh-Samberg, O. (2007): Estimates of Imputed Rent and Analysis of their Distributional Impact in Germany. (Research project "Accurate Income Measurement for the Assessment of Public Policies" (AIMAP), funded by European Commission, 6th Framework Programme, 2006-2009, Contract Nr. CIT5-CT-2005-028412).

Gächter, S. (2008): Improvements and Future Challenges for the Research Infrastructure in the Field "Experimental Economics”. RatSWD Working Paper No. 56.

Geyer, S./Norozi, K./Buchhorn, R. and Wessel, A. (2008): Chances of employment in a population of women and men after surgery of congenital heart disease: Gender-specific comparisons between patients and the general population. SOEPpaper No. 91.

Goebel, J./Wagner, G.G. und Wurm, M. (2010): Exploring the Linkage of Spatial Indicators from Remote Sensing Data with Data from the Socio-Economic Panel (SOEP). SOEPpaper [forthcoming].

Guo, G. (2008): Introduction to the special issue on society and genetics. Sociological Methods \& Research 37 (2), $159-163$.

Guo, G./Tong, Y. and Cai, T. (2008): Gene by Social Context Interactions for Number of Sexual Partners among White Male Youths: Genetics-Informed Sociology. American Journal of Sociology 114 (Supplement), S36-S66.

Grabner, R.H. and Stern, E. (2008): Improvements and future challenges for the research infrastructure in the field "Measuring cognitive ability". RatSWD Working Paper No. 49.

Hank, K./Jürges, H./Schupp, J. and Wagner, G.G. (2009): Isometrische Greifkraft und sozialgerontologische Forschung: Ergebnisse und Analysepotentiale des SHARE und SOEP. Zeitschrift für Gerontologie und Geriatrie 42, 117-126.

Haug, S. (2009): Migration and Statistics. RatSWD Working Paper No. 101.

Headey, B. (2008): Poverty Is Low Consumption and Low Wealth, Not Just Low Income. Social Indicators Research 89, $23-$ 39.

Jahoda, M./Lazarsfeld, P.F. and Zeisel, H. (1933): Marienthal: The Sociography of an Unemployed Community - Translated by the authors with John Reginait and Thomas Elsaesser. Chicago 1971.

Jürges, H. (2009): Provision for Old Age National and International Survey Data to Support Research and Policy on Aging. RatSWD Working Paper No. 94.

Kämper, Eckhard and Manfred Nießen. (2008): Developing the Research Infrastructure in the Social Sciences: The Role and Contribution of the German Research Foundation. RatSWD Working Paper No. 50.

Kalton, G. and Citro, C.F. (1993): Panel Survey: Adding the Forth Dimension. Survey Methodology 19 (2), 205-215. 16 
Kanipe, J. (2009): New Eyes, New Skies. Nature 457 (7225), 18

Kreuter, F. and Casas-Cordero, C. (2010): Paradata. RatSWD Working Paper 136.

Kroeger, K. (2008): “Exit-Interviews” in SOEP und SHARE. DIW Data Documentation No. 40.

Kroh, M./Pischner, R./Spieß, M. and Wagner, G.G. (2008): On the Treatment of Non-Original Sample Members in the German Household Panel Study (SOEP). Methoden - Daten - Analysen 2 (2), 179-198.

Krupp, H.-J. (2008): The German Socio-Economic Panel: How It All Began. SOEPpaper No. 75.

Kruppe, Th./Müller, E./Wichert, L. and Wilke, R.A. (2008): On the Definition of Unemployment and its Implementation in Register Data - The Case of Germany. Schmollers Jahrbuch 128 (3), 461-488.

Laurie, H. and Sullivan, O. (1991): Combining Qualitative and Quantitative Data in the Longitudinal Study of Household Allocations. ISER Working Paper 1991-07.

Lakes, T. (2009): Geodata. RatSWD Working Paper No. 89.

Lazarsfeld, P. and Fiske, M. (1938): The "Panel” as a New Tool for Measuring Opinion. Public Opinion Quarterly 2 (4), 596612.

Lazarsfeld, P.F./Berelson, B. and Gaudet, H. (1944): The People's Choice - How the Voters makes up his Mind in a Presidential Campaign. New York/London.

Liebig, S. (2009): Interdisciplinary Longitudinal Surveys: Linking Individual Data to Organizational Data in Life-course Analysis RatSWD Working Paper No. 68.

Mayer, K.U. (2009): New Directions in Life Course Research. Annual Review of Sociology 35, 413-433.

Mehl, M.R. et al. (2007): Are Women Really More Talkative Than Men? Science 317, 82.

Menard, S. (2002): Longitudinal Research. Second Edition Thousand Oaks.

Merz, J. (2009): Time Use and Time Budget Improvements, Future Challenges and Recommendations. RatSWD Working Paper No. 85.

Meyermann, A./Elsner, J./Schupp, J. and Liebig, S. (2009): Pilotstudie einer surveybasierten Verknüpfung von Personen- und Betriebsdaten - Durchführung sowie Generierung einer Betriebsstudie als nachgelagerte Organisationserhebung zum SOEP-Pretest 2006. DIW Research Notes No. 31.

Naef, M. and Schupp, J. (2009): Measuring Trust: Experiments and Surveys in Contrast and Combination. SOEP Papers on Multidisciplinary Panel Data Research at DIW Berlin No. 167.

National Research Council (2008): Biosocial Surveys. Committee on Advances in Collecting and Utilizing Biological Indicators and Genetic Information in Social Science Surveys. In: Weinstein, M./Vaupel, J.W. and Wachter, K.W. (Eds.): Committee on Population, Division of Behavioral and Social Sciences and Education. Washington.

Plomin, R./DeFries, J.C./McClearn, G.E. and McGuffin, P. (2008): Behavioral Genetics, Fifth Edition. New York.

Rasner, A./Himmelreicher, R.K./Grabka, M.M. and Frick, J.R. (2007): Best of Both Worlds: Preparatory Steps in Matching Survey Data with Administrative Pension Records; The Case of the German Socio-Economic Panel and the Scientific Use File Completed Insurance Biographies 2004. SOEPpaper No. 70.

Rendtel, U. (2009): Teaching and Statistical Training. RatSWD Working Paper No. 81.

Rendtel, U. and Harms, Th. (2009): Weighting and Calibration for Household Surveys. In: Lynn. P. (Ed.): Methodology of Longitudinal Surveys. Chichester.

Riediger, M. (2009): Experience Sampling. RatSWD Working Paper No. 62.

Riediger, M./Schmiedek, F./Wagner, G.G. and Lindenberger, U. (2009): Seeking Pleasure and Seeking Pain: Differences in Prohedonic and Contra-Hedonic Motivation From Adolescence to Old Age. Psychological Science 20 (12), 1529-1535.

Rodgers, J.L./Bard, D.E./Johnson, A./D’Onofrio, B. and Miller, W.B. (2008): The Cross-Generational Mother-DaughterAunt-Niece Design: Establishing Validity of the MDAN Design with NLSY Fertility Variables. Behavioral Genetics 38, 567-578.

Romeu Gordo, L./Motel-Klingebiel, A./Wurm, S. (2009): SOEP as a Source for Research on Ageing - Issues, Measures and Possibilities for Improvement. RatSWD Working Paper No. 83.

Sauer, C./Auspurg, K./Hinz, Th./Liebig, S. and Schupp, J. (2009): Die Bewertung von Erwerbseinkommen: methodische und inhaltliche Analysen zu einer Vignettenstudie im Rahmen des SOEP-Pretest 2008. DIW Data Documentation No. 44.

Schäfer, Ch./Schräpler, J.-P./Müller, K.-R. and Wagner, G.G. (2005): Automatic Identification of Faked and Fraudulent Interviews in Surveys by Two Different Methods. Schmollers Jahrbuch 125 (1), 183-193.

Schoon, I. (2006): Risk and Resilience. Cambridge.

Schräpler, J.-P./Schupp, J. and Wagner, G.G. (2010): Individual and Neighborhood Determinants os Survey Nonresponse An Analysis Based on a New Subsample of the German Socio-Economic Panel (SOEP), Microgeographic Characteristics and Survey-Based Interviewer Characteristic. SOEPpaper [forthcoming].

Schupp, J. and Wagner, G.G. (1995): Die Zuwanderer-Stichprobe des Sozio-oekonomischen Panels (SOEP). Vierteljahrshefte zur Wirtschaftsforschung 64 (1), 16-25.

Schupp, J. and Wagner, G.G. (2010): Zum „Warum“ und „Wie“ der Erhebung von (genetischen) ,Biomarkern’ in sozialwissenschaftlichen Surveys. SOEPpapers on Multidisciplinary Panel Data Research No. 260.

Schupp, J./Siegel, N.A./Erlinghagen, M./Stegmann, T. and Wagner, G.G. (2008): Leben außerhalb Deutschlands - Eine Machbarkeitsstudie zur Realisierung von Auslandsbefragungen auf Basis des Sozio-oekonomischen Panels (SOEP). SOEPpapers on Multidisciplinary Panel Data Research No. 120.

Schupp, J./Spieß, C.K. and Wagner, G.G. (2008): Die verhaltenswissenschaftliche Weiterentwicklung des Erhebungsprogramms des SOEP. Vierteljahrshefte zur Wirtschaftsforschung 77 (3), 63-76. [English Version is forthcoming as a SOEPpaper in 2010].

Schupp, J. (2009): 25 Jahre Sozio-oekonomisches Panel - Ein Infrastrukturprojekt der empirischen Sozial- und Wirtschaftsforschung in Deutschland. Zeitschrift für Soziologie 38 (5), 350-357.

Siedler, Th./Schupp, J./Spieß, C.K. and Wagner, G.G. (2009): SOEP as „Reference Data“. Schmollers Jahrbuch 129 (2), $367-$ 374.

Siegrist, J. (2001): Zukünftige Aufgaben der Sozial-Epidemiologie. In: Mielck, A. and Bloomfield, K. (Eds.): SozialEpidemiologie. Weinheim/Munich.

Spinath, F.M. (2008): Improvements and Future Challenges in the Field of Genetically Sensitive Sample Designs. RatSWD Working Paper No. 45. 
Teddlie, Ch. and Tashakorri, A. (2003): Major Isues and Controversies in the Use of Mixed Mothods in the Social and Behavioral Sciences. In: Tashakorri, A. and Teddlie, Ch. (Eds.): Handbook of Mixed Methods in the Social and Behavioral Research. Thousand Oakes/London/New Delhi.

Uhlig, J./Solga, H. and Schupp, J. (2009): Bildungsungleichheiten und blockierte Lernpotenziale: Welche Bedeutung hat die Persönlichkeitsstruktur für diesen Zusammenhang? Zeitschrift für Soziologie 38 (5), 418-440.

Wagner, G.G./Frick, J.R. and Schupp, J. (2006): Enhancing the Power of Household Panel Studies: The Case of the German Socio-Economic Panel Study (SOEP). Schmollers Jahrbuch 127 (1), 139-169

Wissenschaftsrat (2003): Strategische Forschungsförderung - Empfehlungen zu Kommunikation, Kooperation und Wettbewerb im Wissenschaftssystem. http://www.wissenschaftsrat.de/texte/5654-03.pdf.

Wissenschaftsrat (2009): Science-Policy Statement on the Status and Future Development of the Socio-Economic Panel (SOEP). http://www.wissenschaftsrat.de/texte/9503-09.pdf.

Wissenschaftsrat (2010): Overview of International Household Panel Studies. RatSWD Working Paper 135.

Wrzus, C. et al. (2010): Do Associations Between "Sleeping Well" and "Feeling Well” Become Weaker with Age? Results from the SOEP and an Ambulatory Monitoring Study. Berlin. [Manuscript in preparation]. 